\title{
Halophilic fungi in a polyhaline estuarine habitat
}

\author{
Valerie Gonsalves, Shweta Nayak and Sarita Nazareth* \\ Department of Microbiology, Goa University, Taleigao Plateau, Goa-403206, India. \\ Accepted 23 April, 2012
}

\begin{abstract}
Halophilic mycobiota was isolated from Mandovi estuary and it was dominated by Aspergillus and Penicillium species. Cladosporium and Eurotium were found in lesser numbers while obligate halophiles were found only amongst the aspergilla and they were all identified as Aspergillus penicillioides. Some aspergilli and all the isolates of Penicillium, Cladosporium and Eurotium were facultative halophiles. There were significant differences in growth of each isolate at different salt concentrations. Most of the isolates were euryhaline, having a wide range of salt tolerance; a few were stenohaline, with a narrow range of halotolerance. The isolates were mainly moderate halophiles, with a very few slight halophiles. Isolation of obligate halophilic fungi from polyhaline environment of an estuary is hereby reported for the first time.
\end{abstract}

Key words: Aspergillus penicillioides, obligate halophiles, facultative halophiles.

\section{INTRODUCTION}

An estuary is under the influence of marine conditions such as tides, waves, influx of saline water, as well as the flow of fresh water and sediment of the river (Manoharachary et al., 2005). Studies on the mycobiota in estuarine ecosystems have focused on the diversity or metabolic activities of fungi from estuarine waters, sediments, wood and litter, marshes and mangroves (Borut and Johnson, 1962; Shearer, 1972; Cooke and Lacourse, 1975; Rai and Chowdhery, 1978; D'souza et al., 1979; Maria and Sridhar, 2002; da Silva et al., 2003; Tsui and Hyde, 2004; Anita et al., 2009; Karamchand et al., 2009; Nambiar and Raveendran, 2009; Rani and Panneerselvam, 2009; Pearman et al., 2010; Mohamed and Martiny, 2011). The halophilic nature of these fungi has not been described.

Hypersaline environments have been a focus of study for halophilic organisms that are able to survive in these environments. Gymnascella marismortui was the first halophilic fungi to be isolated from the Dead Sea (Buchalo et al., 1998). The black yeasts and closely related dematiaceous Cladosporium were among the first halophilic fungi to have been isolated from salterns in Secovlje, Slovenia-Adriatic (Gunde-Cimerman et al.,

*Corresponding author. E-mail: saritanazareth@yahoo.com. Tel: 091-832-6519361. Fax: 091-832-2451184/2452889.
2000; Butinar et al., 2005a) and subsequently from Cabo Rojo, Puerto Rico (Diaz-Munoz and Montalvo-Rodriguez, 2005). The isolation of other filamentous fungi from salterns (Cantrell et al., 2006; Nayak et al., 2012), as well as from the Dead Sea (Kis-Papo et al., 2003a, b; Wasser et al., 2003; Nazareth et al., 2012), Mono Lake, California (Steiman et al., 2004), coastal environments of Arctics (Gunde-Cimerman et al., 2005) and from saline soils of Soos, Czech Republic (Hujslova et al., 2010) has followed.

Microbes that inhabit high-salt environments may be of halotolerant or halophilic nature, being adapted to high levels of ions, as well as to low $a_{w}$ (Grant, 2004). Halophiles have been further classified as facultative or obligate (Kushner, 1978; Nazareth et al., 2012).

The occurrence of halophilic filamentous fungi, particularly that of obligate halophilic aspergilli, in a polyhaline estuarine environment, is recorded herein for the first time.

\section{METHODOLOGY}

\section{Samples}

Sampling was done along the estuary of the Mandovi (EM) which flows into the Arabian Sea, on the West Coast of the Indian Peninsula. Samples of top and bottom water (wt) and (wb), and of sediment(s) were obtained using the Niskin and Grab samplers, 


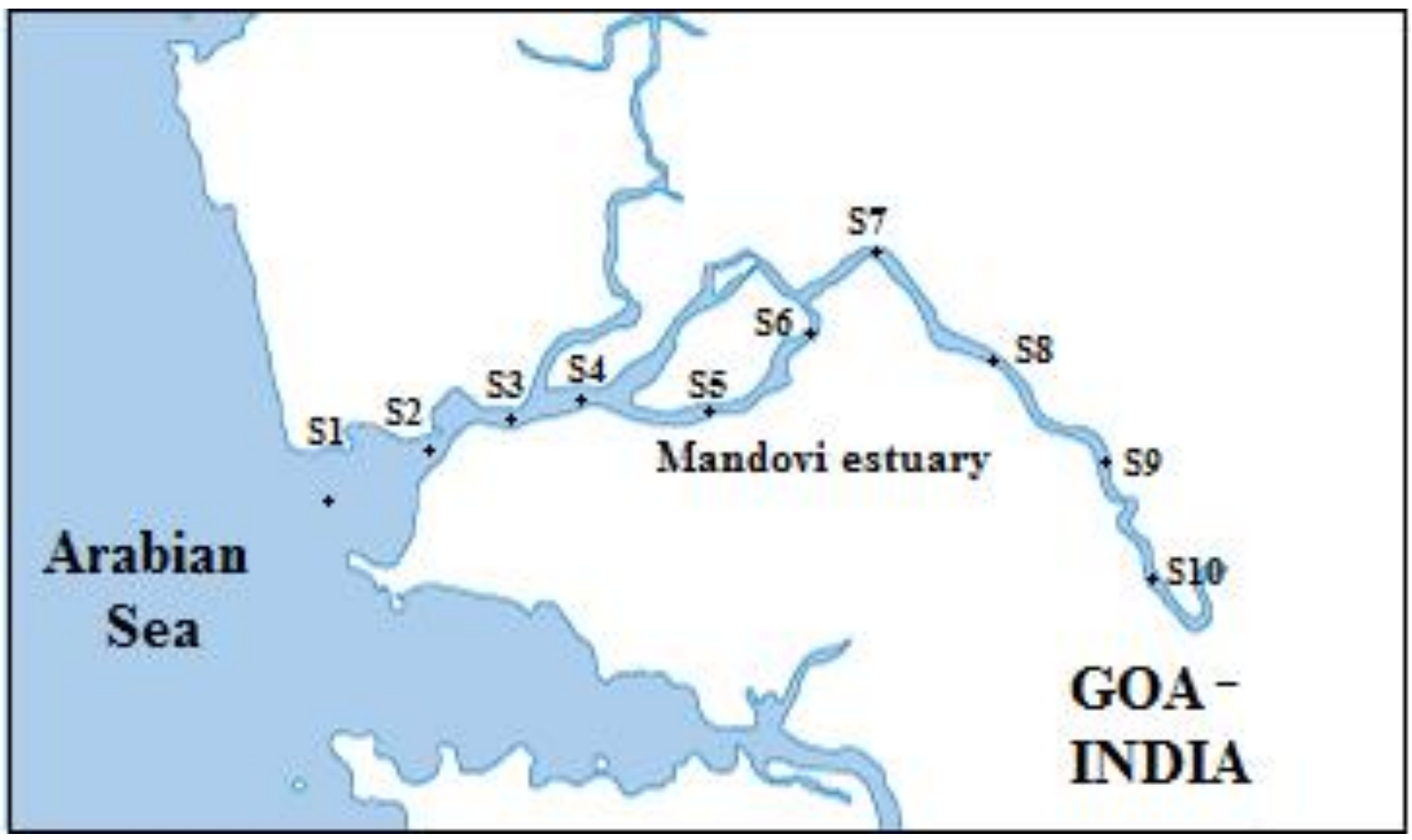

Figure 1. Map indicating the stations of sampling along the Mandovi estuary.

respectively, from 10 Stations, $S 1$ to $S 10$ (Figure 1), beginning at the mouth and moving hinterland between $73^{\circ} 46.65^{\prime}$ to $74^{\circ} 2.5^{\prime}$ longitude (courtesy G. N. Nayak, Goa University), as shown in Figure 1.

The salinity and $\mathrm{pH}$ were measured as described by Nazareth et al. (2012).

\section{Isolation and identification of fungi}

The samples were processed under sterile conditions. The water samples and suspensions of sediment were each plated on to Czapek-Dox Agar $+20 \%$ solar salt $(20 \%$ S-CzA) for isolation of halophilic fungi, which were then incubated at room temperature of about $30^{\circ} \mathrm{C}$, up to 30 days.

The isolates were picked based on dissimilarity in the colony characteristics, purified and numbered according to the station and the sample of top or bottom water and of sediment. Purified isolates were maintained on $10 \% \mathrm{~S}-\mathrm{CzA}$. Fungal identification was done on the basis of colony and micro morphology characteristics with reference to identification keys (Raper and Fennell, 1965; Ellis, 1971; Domsch et al., 1980).

The identification of an obligate halophilic isolate was confirmed by ITS rDNA sequence analysis (Merck-GeNei Services), using consensus primers for 18S rRNA, ITS1, 5.8S rRNA, ITS2 and 28S rRNA gene fragment. A GenBank accession number was obtained. Sequence similarities were obtained using NCBI BLAST. Alignment and phylogenetic tree were constructed in Clustal $X$ version 2 and the NJ distance method.

\section{Halophilic nature of the isolates}

Salt tolerance of the isolates was checked by inoculating the cultures in triplicate on $\mathrm{CzA}$ amended with salt up to concentrations of $30 \% \mathrm{w} / \mathrm{v}$ (Nazareth et al., 2012). Growth was recorded after 7 days incubation in terms of colony diameter; plates that did not show growth in 7 days were further incubated till 15 days to check for delayed growth and then sub-cultured onto corresponding media to confirm the salt tolerance level. Salt tolerance curves were obtained by plotting the arithmetic mean of colony diameter with the standard error.

Statistically significant difference $(P<0.05)$ in the effect of different salt concentrations on growth of all isolates, as well as in growth within the species, was analyzed by two-way ANOVA.

\section{RESULTS}

\section{Sample Salinity and $\mathrm{pH}$}

The salinity of the surface water was comparable to that of the bottom water at all stations. The salinity at $\mathrm{S} 1$ at the mouth of the estuary was $37 \%$, close to that of sea water, with a gradual decrease to approximately 30 to $31 \%$ at S5; it decreased drastically to approximately 24 to $25 \%$ at S6 and S7 and further there was a sequential decrease to approximately 10 to $16 \%$ till the last station. The sediment had a salinity of $5 \%$ at S6 and $10 \%$ at the rest of the stations, which was comparatively much lower than that of the water column at all stations.

The $\mathrm{pH}$ of the samples was around neutral.

\section{Fungal isolates}

The isolates obtained belonged to the genera of 
Table 1. Species identification of isolates from different stations.

\begin{tabular}{|c|c|}
\hline Species & Isolate number \\
\hline A. flavus & EM2s111, EM7w 140 \\
\hline A. fumigatus & EM2s112, EM4w $119, E_{t}$ Ew $w_{b} 135$ \\
\hline A. nidulans & $E M 5 w_{t} 129$ \\
\hline A. penicillioides & $\begin{array}{l}E M 2 w_{b} 107, E M 4 w_{t} 118, E M 4 w_{t} 120, E M 4 w_{b} 121, E M 4 w_{b} 123, E M 4 w_{b} 125, E M 5 w_{t} 130, E M 6 w_{t} 133, E M 6 s 137, \\
E M 7 w_{t} 138, E M 7 w_{t} 139, E M 7 w_{b} 141, E M 7 w_{b} 142, E M 7 w_{b} 143, E M 7 s 144, E M 7 s 145, E M 8 w_{t} 146, E M 8 w_{t} 147, \\
E M 8 w_{t} 148, E M 8 w_{b} 149, E M 9 w_{b} 155, E M 8 s 153, E M 9 s 156\end{array}$ \\
\hline A. sydowii & EM8s 152 \\
\hline A. versicolor & $E M 2 w_{t} 104, E M 2 w_{t} 105, E M 2 w_{t} 106, E M 2 w_{b} 108, E M 2 s 110, E M 6 w_{b} 136$ \\
\hline $\begin{array}{l}P \text {. asymetrica sub- } \\
\text { section fasciculata }\end{array}$ & EM5wb131, EM8s151 \\
\hline P. canescens & EM1 $w_{b} 101$ \\
\hline P. chrysogenum & EM1s103, EM6wt134 \\
\hline P. corylophilum & EM2s109, EM3wb114, EM5s132, EM8s150 \\
\hline P. steckii & $E M 1 w_{t} 102, E M 3 w_{t} 113, E M 3 s 115, E M 4 w_{t} 117$ \\
\hline E. amstelodami & $E M 4 w_{b} 124$ \\
\hline E. repens & EM3s116, EM4s126, EM4s127 \\
\hline C. carpophilum. & EM9w 154 \\
\hline C. cladosporioides & $E M 4 w_{b} 122, E M 4 s 128$ \\
\hline
\end{tabular}

Aspergillus, Penicillium, Cladosporium and Eurotium (Table 1). Culturally dissimilar isolates from each sample were picked and identified as Aspergillus: A. flavus, $A$. fumigatus, $A$. nidulans, $A$. penicillioides, A. sydowii, $A$. versicolor; Penicillium: $P$. asymetrica subsection fasciculata, $P$. canescens, $P$. chrysogenum, $P$. corylophilum, P. steckii; Cladosporium: C. cladosporioides and C. carpophilum and Eurotium: $E$. amstelodami and E. repens.

\section{Halophilic nature of the isolates}

The isolates that did not grow in absence of salt were characterized as obligate halophiles and those that grew in absence of added salt, but showed enhanced growth at increased levels of salt were termed as facultative halophiles. The halotolerance curves of the isolates are presented according to their obligate or facultative halophilic nature as shown in Figures $2 a$ and $b$, respectively.

\section{Obligate halophiles}

Twenty-three obligate halophiles were obtained, all identified as $A$. penicillioides. These required a minimum of 2,5 or $10 \%$ salt for growth (Figure $2 \mathrm{a}$ ). Most were moderate halophiles, with optimal growth at $10 \%$ salt, and two at $5 \%$ salt. Most showed a euryhaline nature, having a capacity to grow on a wide range of salt concentrations up to $20 \%$ or even $30 \%$ salt; three showed a stenohaline characteristic, with a narrow range of salt tolerance of 5 to $15 \%$. Significant difference $(P<0.05)$ was obtained in the growth at different salt concentrations, as well as in the halotolerance curves of the isolates.

The isolates were obtained mainly from samples of top or bottom water, or sediment of S4 - S9. A. penicillioides had a very different appearance in colony characteristics from the other aspergilli, forming comparatively small colonies with a compact, tough felt growth and furrowed appearance; this also ensured that such isolates were picked from each of the samples in which they were found. Identification of a representative isolate, EM6s137, was confirmed by gene sequence analysis as $A$. penicillioides, the GenBank accession number given as JQ240645. The phylogenetic relationship of this isolate is shown in Figure 3.

\section{Facultative halophiles}

Thirteen isolates of aspergilli and all isolates of Penicillium, Cladosporium and Eurotium were facultative halophiles, randomly distributed throughout the stations; Cladosporium was isolated only from bottom water and sediment samples.

The isolates of $A$. sydowii and $A$. penicillioides showed maximal growth at $10 \%$ salt and could grow at salt concentrations up to 25 and $30 \%$, respectively; $A$. fumigatus and $A$. nidulans isolates grew maximally at salt concentration of $5 \%$ and $A$. versicolor isolates showed 


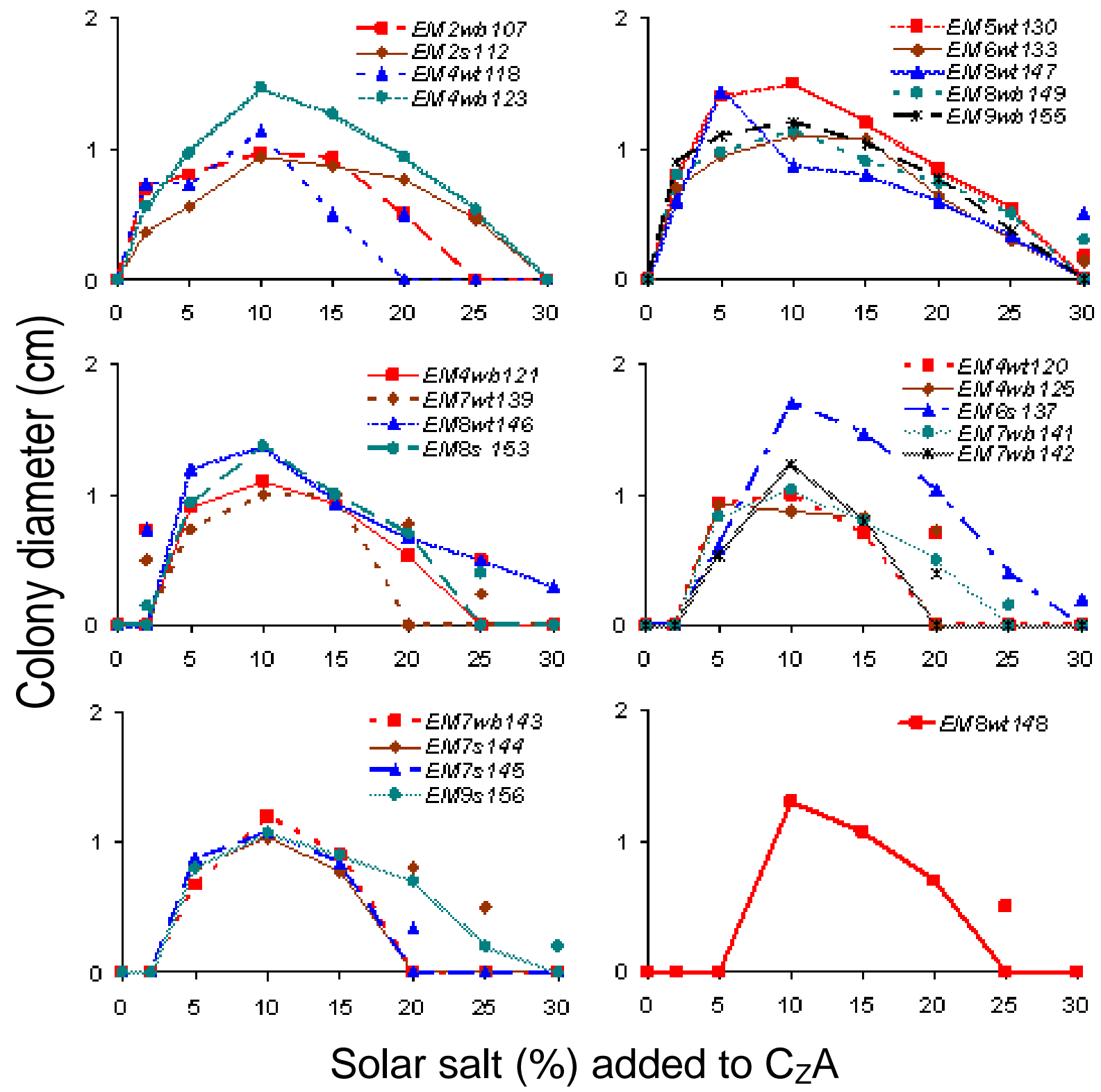

Figure 2a. Salt tolerance curves of obligate halophilic $A$. penicillioides as recorded after $7 \mathrm{~d}$ incubation; unconnected symbols indicate delayed growth at respective salt concentrations, after $15 \mathrm{~d}$ incubation.

optimum growth at 2 to $10 \%$ salt, with a tolerance level of 20 to $25 \%$ salt; $A$. flavus isolates had optimal growth in presence of 2 and $10 \%$ salt and tolerated a concentration of 15 and $25 \%$ salt, respectively.

The isolates of $P$. asymetrica subsection fasciculata, $P$. canescens and $P$. chrysogenum grew optimally at $5 \%$ salt and exhibited a tolerance level of 20 to $30 \%$ salt; $P$. corylophilum showed optimal growth with 2 or $5 \%$ salt, and P. steckii with 5 or $10 \%$ salt, all able to grow in presence of 20 to $25 \%$ salt.

Salt concentrations of 2 and $5 \%$ supported optimal growth of C. cladosporioides and C. carpophilum, respectively; these species tolerated a maximum of $20 \%$ salt. Isolates of Eurotium: E. amstelodami and E. repens showed maximum growth in presence of 2 or $5 \%$ salt, and tolerance to 20 to $25 \%$.

The isolates were euryhaline in nature, most of which were moderate halophiles; some grew optimally with $2 \%$ salt and were termed as slight halophiles. Significant difference $(P<0.05)$ was obtained in the growth of a given species at different salt concentrations, as well as between the strains of species of $A$. versicolor, $P$. corylophilum and $P$. steckii; however, similarity was found in the growth of strains of $P$. asymetrica subsection fasciculata, of $P$. chrysogenum, of $E$. repens and of $C$. cladosporioides. 

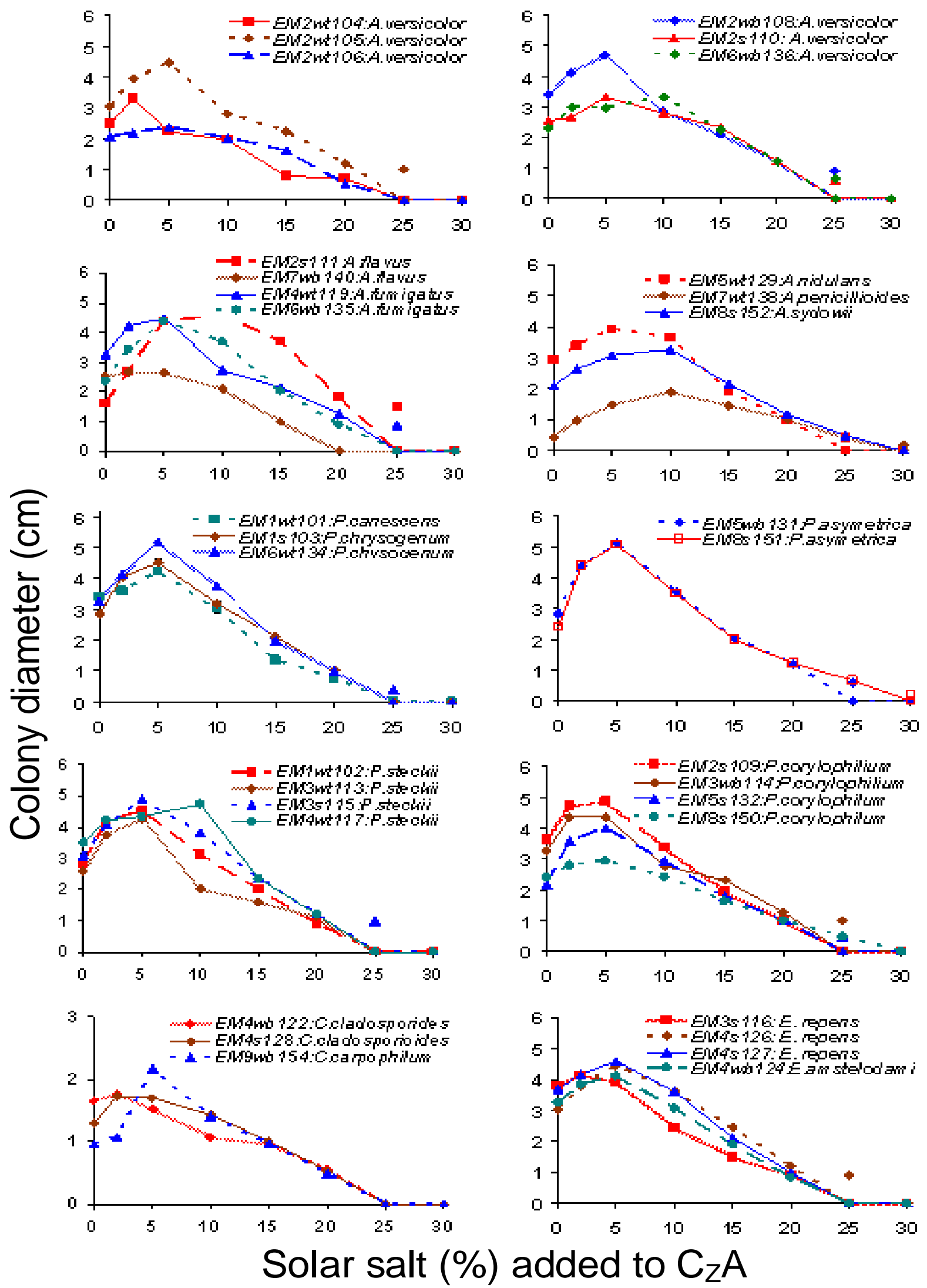

Figure 2b. Salt tolerance curves of facultative halophililc Aspergillus, Penicillium, Cladosporium and Eurotium as recorded after 7d incubation; unconnected symbols indicate delayed growth at respective salt concentrations, after $15 \mathrm{~d}$ incubation. 


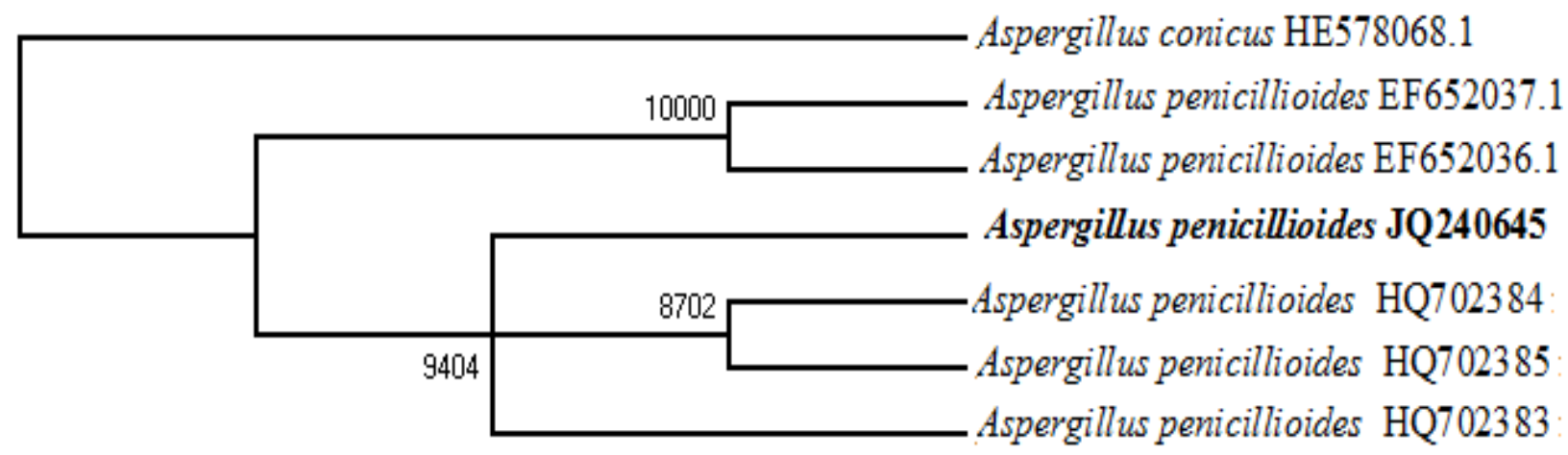

Figure 3. Phylogenetic tree obtained from the alignment of ITS region of rDNA of $A$. penicillioides species; the isolate $A$. penicillioides JQ240645 was obtained during the present study.

\section{DISCUSSION}

The work demonstrates the presence of moderate halophiles, in particular, the obligate halophile $A$. penicillioides, as well as other species belonging to the genera Aspergillus, Penicillium, Eurotium and Cladosporium, in the polyhaline environment of the estuary. The high concentration of salt used in the media for isolation, helped in the selective isolation of halophilic fungi over that of the non-halophiles.

Aspergillus and Penicillium were the dominant halophilic genera; Eurotium and Cladosporium were isolated in lesser numbers. While the genus Aspergillus had both obligate and facultative halophiles, Penicillium, Cladosporium and Eurotium species were exclusively facultative halophiles. These results corroborate earlier findings (Nazareth et al., 2012; Nayak et al., 2012). The obligate halophiles, by means of their absolute requirement for salt, are truly of marine origin. The facultative halophiles could be from terrestrial or fresh water environment, which have adapted so as to grow and sporulate in marine environment.

It was observed that the obligate halophilic $A$. penicillioides were found in greater numbers at the stations hinterland, although the salinity was lower, as compared to that at the mouth, where the salinity was nearly equal to that of sea water. Similar results were reported by Borut and Johnson (1962) wherein marine fungi were isolated from fresh and brackish sediments of an estuary, the irregular pattern of water currents giving rise to changes in environmental factors as well as determining the direction and extent of spore transport.

The presence of obligate halophiles upstream could be due to their ability to synthesize or take up compatible solutes from the estuarine environment, which is abundantly lined with mangroves. Tolerance of salinity has been viewed as a partial function of nutrient level (Borut and Johnson, 1962). It has been reported that fungi associated with standing litter of macrophytes could adapt to daily fluctuations of water availability through adjustment of their intracellular solute concentrations by degradation of organic matter (Kuehn et al., 1998). It is known that in estuarine ecosystems, the detritus and marsh vegetation constitute a major part of the organic content (Manoharachary et al., 2005). The mangroves bordering the estuary, are more abundant upstream, where there is also a decrease in the cross-sectional area, and would serve as a nutrient source for the obligate halophiles. Earlier results have in deed shown the presence of the obligate halophile $A$. penicillioides in mangroves bordering the Mandovi estuary (Nayak et al., 2012). Tidal movement which extends to a distance of about $50 \mathrm{~km}$ (Sundar and Shetye, 2005), a point just beyond station 10, would aid the availability of the nutrient, the receding tide bringing particulate material from upstream of the estuary, and the rising tides carrying it back, thereby forming a nutrient reservoir (Verma and Agarwal, 2007). Interestingly, no halophile was obtained from the samples from station 10 hinterland where there were no mangroves.

Earlier reports have focused on isolation of halophiles only from hypersaline econiches (Buchalo et al., 1998; Gunde-Cimerman et al., 2000; Kis Papo et al., 2003a, b; Wasser et al., 2003; Steiman et al., 2004; Butinar et al., 2005a,b; Diaz-Munoz and Montalvo-Rodriguez, 2005; Gunde-Cimerman et al., 2005; Cantrell et al., 2006; Gunde-Cimerman et al., 2009; Hujslova et al., 2010; Nazareth et al., 2012; Nayak et al., 2012), which are expected to support the growth of such organisms. However, recent work records the finding of obligate halophiles from brackish waters of mangroves, with a salinity of $32 \%$ (Nayak et al., 2012). In this work, obligate halophiles were found in the polyhaline waters of the estuary, at a salinity range of 12 to $33 \%$.

This work demonstrates the occurrence of obligate moderately halophilic aspergilli in estuarine environment having salinity lower than that of the sea, thus indicating that hypersaline environments are not the sole econiches for true halophiles.

This is a first report on the isolation and description of an obligate halophilic $A$. penicillioides species from a polyhaline environment of an estuary. 


\section{ACKNOWLEDGEMENT}

Authors are grateful to Mofeeda Gazem for help in the identification of the fungi.

\section{REFERENCES}

Anita DD, Sridhar KR, Bhat R (2009). Diversity of fungi associated with mangrove legume Sesbania bispinosa (Jacq.) W. Wight (Fabaceae). Livest. Res. Rur. Dev., 25(1): 67.

Borut SY, Johnson Jr. TW (1962). Some biological observations on fungi in estuarine sediments. Mycologia, 54(2): 181-193.

Buchalo AS, Nevo E, Wasser SP, Oren A, Molitoris HP (1998). Fungal life in the extremely hypersaline water of the Dead Sea: first records. Proc. R. Soc. Lon., 265: 1461-1465.

Butinar L, Sonjak S, Zalar P, Plemenitas A, Gunde-Cimerman N (2005a). Melanized halophilic fungi are eukaryotic members of microbial communities in hypersaline waters of solar salterns. Bot. Mar., 48: 73-79.

Butinar L, Zalar P, Frisvad JC, Gunde-Cimerman N (2005b). The genus Eurotium - members of indigenous fungal community in hypersaline waters of salterns. FEMS Microbiol. Ecol., 51: 155-166.

Cantrell SA, Casillas-Martinez L, Molina M (2006). Characterization of fungi from hypersaline environments of solar salterns using morphological and molecular techniques. Mycol. Res., 110: 962-970.

Cooke JC, LaCourse JR (1975). Preliminary Study of Microfungi from the Connecticut River Estuary. B. Torrey Bot. Club, 102(1): 1-6.

da Silva M, Umbuzeiro GA, Pfenning LH, Canhos VP, Esposito E (2003). Filamentous fungi isolated from estuarine sediments contaminated with industrial discharges. Soil Sediment Contam., 12(3): 345-356.

Diaz-Munoz G, Montalvo-Rodriguez R (2005). Halophilic black yeasts Hortaea wernekii in the Cabo Rojo Solar Salterns: its first record for this extreme environment in Puerto Rico. Caribb. J. Sci. 41: 360-365.

Domsch KH, Gams W, Anderson TH (1980). Compendium of Soil Fungi IHW-Verlag, Eching, p. 1.

D'Souza J, Araujo A, Karande A, Freitas YM (1979). Studies on fung from coastal waters of Bombay and Goa. Ind. J. Mar. Sci., 8(2): 98102.

Ellis MB (1971). Dermatiaceous hyphomycetes. Commonwealth mycological institute, Kew Surrey England.

Grant WD (2004). Life at low water activity. Phil. Trans. R. Soc. Lond. B., 359: 1249-1267.

Gunde-Cimerman N, Zalar P, De Hoog GS, Plemenitas A (2000). Hypersaline waters in salterns: natural ecological niches for halophilic black yeasts. FEMS Microbiol. Ecol., 32: 235-240.

Gunde-Cimerman N, Butinar L, Sonjak S, Turk M, Uršic V, Zalar P, Plemenitaš A (2005). Halotolerant and halophilic fungi from coastal environments in the Arctics. In: Gunde-Cimerman N, Oren A, Plemenitaš A (eds) Adaptation to life at high salt concentrations in Archaea, Bacteria and Eukarya. Springer, Netherlands, pp. 397-423.

Gunde-Cimerman N, Ramos J, Plemenitas A (2009). Halotolerant and halophilic fungi. Mycol. Res. 113: 1231-1241.

Hujslova M, Kubatova A, Chudickova M, Kolarik M (2010). Diversity of fungal communities in saline and acidic soils in the Soos National Natural Reserve, Czech Republic. Mycol. Progr., 9: 1-15.

Karamchand KS, Sridhar KR, Bhat R (2009). Diversity of fungi associated with estuarine sedge Cyperus malaccensis Lam. J. Agr. Tech., 5(1): 111-127.

Kis-Papo T, Grishkan I, Gunde-Cimerman N, Oren A, Wasser SP, Nevo $E$ (2003a). Spatiotemporal patterns of filamentous fungi in the hypersaline Dead Sea. In: Nevo E, Oren A, Wasser SP (eds) Fungal Life in the Dead Sea. Gantner Verlag, Ruggel, pp. 271-292.

Kis-Papo T, Oren A, Wasser SP, Nevo E (2003b). Survival of filamentous fungi in hypersaline Dead Sea water. Microbial. Ecol., 45: 183-190.
Kuehn KA, Churchill PF, Suberkropp K (1998). Osmoregulatory Responses of Fungi Inhabiting Standing Litter of the Freshwater Emergent Macrophyte Juncus effuses. Appl. Environ. Microb., 64(2): 607-612.

Kushner DJ (1978). Life in high salt and solute concentrations. In: Kushner DJ (ed) Microbial Life in Extreme Environments. Academic Press, London, pp. 317-368.

Manoharachary C, Sridhar K, Singh R, Adholeya A, Suryanarayanan TS, Rawat S, Johri BN (2005). Fungal biodiversity: Distribution, conservation and prospecting of fungi from India. Curr. Sci. Ind., 89(1): 58-71.

Maria GL, Sridhar KR (2002). Richness and diversity of filamentous fungi on woody litter of mangroves along the west coast of India. Curr. Sci. Ind., 83(12): 1573-1580.

Mohamed DJ, Martiny JBH (2011). Patterns of fungal diversity and composition along a salinity gradient. Int. Soc. Microb. Ecol., 5: 379388.

Nambiar GR, Raveendran K (2009). Frequency and abundance of marine mycoflora in mangrove ecosystem of North Malabar, Kerala (India). Acad. Plant Sci., 2(2): 65-68.

Nayak S, Gonsalves V, Nazareth S (2012). Isolation and salt tolerance of halophilic fungi from mangroves and solar salterns in Goa - India. Indian J. Mar. Sci. (In Press).

Nazareth S, Gonsalves V, Nayak S (2012). A first record of obligate halophilic aspergilli from the Dead Sea. Indian J. Microbiol., 52: 22 27.

Pearman JK, Taylor JE, Kinghorn JR (2010). Fungi in aquatic habitats near St Andrews in Scotland. Mycosphere, 1: 11-21.

Rai JN, Chowdhery HJ (1978). Microfungi from mangrove swamps of West Bengal. India Geophytology, 8(1): 103-110.

Rani C, Panneerselvam A (2009). Diversity of lignicolous marine fungi recorded from Muthupet environs, east coast of India. J. Agr. Biol. Sci., 4(5): 1-6.

Raper KB, Fennell DI (1965). The Genus Aspergillus. Williams and Wilkins Co, Baltimore.

Shearer CA (1972). Fungi of the Chesapeake Bay and Its Tributaries. III. The Distribution of Wood-InhabitingAscomycetes and Fungi Imperfecti of the Patuxent River. Am. J. Bot., 59(9): 961-969.

Steiman R, Ford L, Ducros V, Lafond JL, Guiraud P (2004). First survey of fungi in hypersaline soil and water of Mono Lake area (California). Antonie van Leeuwenhoek, 85: 69-83.

Sundar D, Shetye SR (2005). Tides in the Mandovi and Zuari estuaries, Goa, west coast of India. J. Earth Syst. Sci., 114(5): 493-503.

Tsui CKM, Hyde KD (2004). Biodiversity of fungi on submerged wood in a stream and estuary in the Tai Ho Bay, Hong Kong. Fungal Divers., 15: 205-220.

Verma PS, Agarwal VK (2007). Cell biology, genetics, molecular biology, evolution and ecology. S Chand and Company Ltd, New Delhi.

Wasser SP, Grishkan I, Kis-Papo T, Buchalo AS, Paul AV, GundeCimerman N, Zalar P, Nevo E (2003). Species diversity of the Dead Sea fungi. In: Nevo E, Oren A, Wasser SP (eds) Fungal Life in the Dead Sea. Gantner Verlag, Ruggel, pp. 203-270. 